\title{
Is innovation in surgery less than ideal? A case study of acellular dermal matrix assisted prosthetic breast reconstruction
}

\author{
Shelley Potter ${ }^{1,4}$, Danielle Browning ${ }^{5}$, Jelena Savovic ${ }^{1}$, Rob Warr ${ }^{3}$, Simon Cawthorn², Jane Blazeby ${ }^{1,4^{*}}$ \\ From 2nd Clinical Trials Methodology Conference: Methodology Matters \\ Edinburgh, UK. 18-19 November 2013
}

\section{Introduction}

The introduction of innovative procedures requires appropriate evaluation. IDEAL recommendations propose four stages of evaluation, (Idea-DevelopmentEvaluation-Assessment-Long-term study). The aim of this study was to review the introduction of an innovative surgical technique according to this framework.

\section{Methods}

Literature searches identified articles published between 2000 and 2012 reporting acellular dermal matrixassisted prosthetic breast reconstruction (ADMPBR). Studies were classified by IDEAL-stage as A)descriptive (IDEAL-1/2a) reporting the feasibility or development of ADMPBR or B)comparative (IDEAL-2b/3(RCTs) comparing ADMPBR with standard techniques. IDEAL study designs reported before and after 2008/9 were examined to explore progression of study design over time.

\section{Results}

Of 236 abstracts, 50 papers reporting data on 3,648 patients were included. 24 (48.0\%) were IDEAL-1/2a;25 (50.0\%) IDEAL-2b and 1 (2\%) IDEAL-3. IDEAL-2bstudies significantly increased from period-1 (2005$2008)$ to period-2 $(2009-2012)(\mathrm{n}=1$ to $\mathrm{n}=24, \mathrm{p}<0.01)$. The number of IDEAL-1/2a-studies published annually remained constant $(n=2-4)$. Almost all IDEAL-1/2a studies $(n=20,87.0 \%)$ provided comprehensive descriptions of surgical technique, but less than half $(\mathrm{n}=11)$ reported patient-selection criteria and only $25 \%$ documented seeking patient consent IDEAL-2b-studies were significantly larger than IDEAL-1/2a-studies (IDEAL-1/ $2 \mathrm{a}-$ median $=39$, inter-quartile range-20-65 vs.IDEAL$2 \mathrm{~b}-$ median $=73$, inter-quartile range- $36-186, \mathrm{p}<0.01$, Median-test) and more likely to report combined results from groups of surgeons $(n=10$ vs. $n=5 ; p=0.06)$. Shortterm complication reporting was more comprehensive in IDEAL-2b-studies but there were no differences in the reporting of histological or technical details across groups and IDEAL-1/2a-studies were significantly more likely to report long-term $(\mathrm{p}=0.03)$, patient-reported $(\mathrm{p}<0.01)$ and cosmetic outcomes $(\mathrm{p}=0.05)$.

\section{Conclusions}

The introduction of ADMPBR does not consider previous evidence and comparative studies are lacking. Welldesigned and conducted studies are needed to appropriately evaluate novel surgical innovations to establish standards of care, protect patients and surgeons.

\section{Authors' details \\ ${ }^{1}$ Centre for Surgical Research, University of Bristol, Bristol, UK. ${ }^{2}$ Breast Care Centre, North Bristol NHS Trust, Bristol, UK. ${ }^{3}$ Department of Plastic Surgery, North Bristol NHS Trust, Bristol, UK. ${ }^{4}$ Division of Surgery, Head and Neck, University Hospitals Bristol NHS Foundation Trust, Bristol, UK. ${ }^{5}$ Department of Surgery, Royal United Hospital Bath, Bath, UK.}

Published: 29 November 2013

doi:10.1186/1745-6215-14-S1-P1

Cite this article as: Potter et al:: Is innovation in surgery less than ideal? A case study of acellular dermal matrix assisted prosthetic breast reconstruction. Trials 2013 14(Suppl 1):P1.

${ }^{1}$ Centre for Surgical Research, University of Bristol, Bristol, UK

Full list of author information is available at the end of the article

C 2013 Potter et al; licensee BioMed Central Ltd. This is an Open Access article distributed under the terms of the Creative Commons 